\title{
A safer step-by-step approach for erector spinae plane phenol neurolytic blocks
}

\author{
Andrés Rocha-Romero, MD i] • Ángel Manuel Juárez-Lemus, MD, ASRA-PMUC, CIPS • \\ Berenice Carolina Hernández-Porras, MD, FIPP
}

Received: 3 November 2020/Revised: 30 November 2020/Accepted: 30 November 2020/Published online: 8 January 2021

(c) Canadian Anesthesiologists' Society 2021

To the Editor,

We read with great interest the recent letter by Elkoundi et al. ${ }^{1}$ about the concern with the erector spinae plane (ESP) phenol neurolytic block. We would like to illustrate our own experience performing what we consider a safer step-by-step approach to this block.

A 67-year-old woman (who consented to this report) diagnosed with breast cancer and chest wall recurrence was referred to our pain management centre. She had undergone modified radical mastectomy and several courses of chemotherapy and radiotherapy. Despite this, her cancer progressed and she later developed carcinoma en cuirasse, a rare form of metastatic cutaneous carcinoma. Its clinical presentation can be divided into two stages. First, erythema that can be confused with dermatitis, and second, a thick leathery skin with indurations that coalesce. $^{2}$ Every step is characterized by burning pain and functional impairment. Her chest wall skin was diffusely indurated and ulcerated. The patient had severe dysesthesias with burning pain all around the left hemithorax. Despite multimodal treatment with duloxetine $120 \mathrm{mg} \cdot \mathrm{day}^{-1}$, fentanyl patches $125 \mu \mathrm{g} \cdot \mathrm{hr}^{-1}$,

This letter is accompanied by a reply. Please see Can J Anesth 2021; this issue.

\footnotetext{
A. Rocha-Romero, MD ( $\square)$.

Department of Anesthesia and Pain Management, Centro

Nacional de Rehabilitación, Hospital de trauma, San José,

Costa Rica

e-mail: rocharomeroandres@gmail.com

Á. M. Juárez-Lemus, MD, ASRA-PMUC, CIPS

B. C. Hernández-Porras, MD, FIPP

Instituto Nacional de Cancerología, Mexico City, Mexico
}

and up to six daily rescue doses of morphine $15 \mathrm{mg}$, her pain score was reported as 9/10. After discussion with the patient and her relatives, an ESP block was scheduled.

The procedure was performed in a sitting position using an Affinity $70 \AA$ (Phillips, The Netherlands) ultrasound with a convex low-frequency probe to identify the left T5 transverse process. Twenty millilitres of $0.25 \%$ levobupivacaine with $4 \mathrm{mg}$ dexamethasone were administered. Thirty minutes post-injection, her pain decreased from $9 / 10$ to $1 / 10$. One week later, the patient suffered a hip fracture, which required a left hip replacement. She was also anticoagulated because of a postoperative deep vein thrombosis. A further week later, the patient reported increasing pain in the left hemithorax, for which an ESP catheter at the T5 level was inserted; she received a $20 \mathrm{~mL}$ bupivacaine $0.25 \%$ bolus, twice daily. A month later, the patient reported increasing pain, in part due to displacement of the ESP catheter. We replaced the catheter and again the pain management was satisfactory with similar twice daily injections. After the need for an additional replacement of the catheter, and given the patient's advanced malignancy and fragile condition, phenol neurolysis was discussed to avoid additional interventions and exposure, particularly considering the coronavirus disease pandemic. For the neurolytic block, a total volume of $17 \mathrm{~mL}$ of $5 \%$ phenol aqueous solution was injected in fractional doses of $1 \mathrm{~mL} \cdot \mathrm{min}^{-1}$; at $30 \mathrm{~min}$ postinjection she reported a warm feeling replacing that of the prior pain. One week later, her pain intensity was reported as $2 / 10$. No further rescue analgesia was required; she died two weeks later.

We previously described ESP phenol spread ${ }^{3}$ and have subsequently obtained satisfactory results in several patients, similar to what others have reported. ${ }^{4}$ Although 
Elkoundi et al. ${ }^{1}$ highlighted the potential effect on the dorsal rami, this should not be a great concern, particularly as this is a typical target for pain physicians treating facet joint pain with radiofrequency ablation. ${ }^{5}$ Previous publications rapidly transition from a diagnostic ESP block to a neurolytic block. Nevertheless, we suggest a more step-wise approach first beginning with a diagnostic block, then a catheter infusion step, and finally the phenol neurolysis. This allows for better confirmation of the technique's analgesic effect before proceeding with neurolysis. Our slow phenol injection, and other reports of its use, suggest that this approach is safe.

Disclosures None.

Funding statement None.

Editorial responsibility This submission was handled by Dr. Hilary P. Grocott, Editor-in-Chief, Canadian Journal of Anesthesia.

\section{References}

1. Elkoundi A, Kartite N, Doghmi N, Baite A. Safety of neurolytic erector spinae plane blocks for cancer pain. Can J Anesth 2020; 67: 1298-9.

2. Culver AL, Metter DM, Pippen JE Jr. Carcinoma en cuirasse. Proc (Bayl Univ Med Cent) 2019; 32: 263-5.

3. Hernandez-Porras BC, Rocha-Romero A, Juarez AM. Phenol spread in erector spinae plane block for cancer pain. Reg Anesth Pain Med 2020; DOI: https://doi.org/10.1136/rapm-2019-100509

4. Papa P, Antunez-Maciel M, Asenjo JF. Cancer shoulder pain treated with a neurolytic erector spinae plane block. Can J Anesth 2020; DOI: https://doi.org/10.1007/s12630-020-01633-4

5. Cohen SP, Bhaskar A, Bhatia A, et al. Consensus practice guidelines on interventions for lumbar facet joint pain from a multispecialty, international working group. Reg Anesth Pain Med 2020; 45: 424-67.

Publisher's Note Springer Nature remains neutral with regard to jurisdictional claims in published maps and institutional affiliations. 